\title{
Sensitivity assay of polymerase chain reaction for detection of Canine Parvo Virus infection in dogs
}

\author{
Prashant Sharma*, Amit Rastogi, Kartikaye Kukreti, Partap Singh Narwal \\ Central Military Veterinary Laboratory, Meerut, India \\ Email: *Prashant.bio@gmail.com
}

Received 10 June 2012; revised 13 July 2012; accepted 12 August 2012

\begin{abstract}
A polymerase chain reaction was performed using reported primers for detection of Canine Parvo Virus (CPV) in the stool sample obtained from repository. The PCR primers were specific to VP1/VP2 gene of CPV. Sensitivity assay of PCR detection was performed by making dilutions of CPV positive DNA extracted from fecal sample, carrying out PCR for each dilution and visualizing amplicons in ethidium bromide stained agarose gel under UV radiation. Study was valuable in determining the efficiency of PCR. The sensitivity of PCR in present study was determined to be equivalent to detection of $0.002 \mathrm{pg} / \mu \mathrm{L}$ of CPV DNA. The study was conducted to analyze the variation, sensitivity and repeatability.
\end{abstract}

Keywords: CPV; Canine Parvo Virus; PCR; Polymerase Chain Reaction; Sensitivity

\section{INTRODUCTION}

$\mathrm{CPV}$ is a single stranded DNA virus and is a major pathogen of dogs. The virus is known to cause myocarditis in young puppies and hemorrhagic gastroenteritis in older animals. Over a period of time enteric form of disease has predominated and it persists as a major problem in breeding kennels, or where vaccination is widely practiced [1]. The presence of CPV in India has been confirmed by Ramadass and Khader [2]. Strain of CPV present in India has been documented to be CPV 2a [3]. Although the disease is vaccinated against; there is still a chance of vaccine failure amongst pups. If neglected there is always probability of full blown disease. In organized kennel, an outbreak may result in huge morbidity and mortality; hence it is essential that presence of infectious agent is detected in shortest possible time, before organism can cause disease. DNA based detection using PCR is one of the most precise and rapid method

*Corresponding author. for detection of CPV. Present study was undertaken to estimate the minimum detection limit of PCR established in laboratory using reported primers for CPV.

\section{MATERIALS AND METHODS}

\subsection{Sample}

Portion of CPV positive feces from Pup number 18 was taken from repository and utilized for the study. DNA was extracted and PCR was carried out to check Pup number 18 positive DNA for CPV. The concentration of extracted DNA was estimated to be $8.3 \mathrm{ng} / \mu \mathrm{L}$ by spectrophotometric analysis carried out at Department of Biotechnology, All India Institute of Medical Sciences, (AIIMS), New Delhi, India.

\subsection{Primers for $P C R$}

Already reported primers C4A (5'-CAAATAGAGCATTGGGCTTACC-3') and C4B (5'-CAATCTCCTTCTGGATATCTTC-3') [4] amplifying VP1/VP2 gene of CPV were used.

\subsection{Amplification}

DNA was extracted using Qiagen DNA Extraction kit according to the protocol supplied with it. The PCR assay mixture $(25 \mu \mathrm{L})$ contained primers $(2 \mu \mathrm{M} / \mathrm{L}$ each), 1X-PCR buffer [ $750 \mathrm{mM} / \mathrm{L}$ Tris HCL (pH 8.8 at $25^{\circ} \mathrm{C}$ ), $200 \mathrm{mM}\left(\mathrm{NH}_{4}\right)_{2} \mathrm{SO}_{4}, 0.1 \%$ Tween-20], $1.5 \mathrm{mM} / \mathrm{L} \mathrm{MgCl}_{2}$, $160 \mu \mathrm{M} / \mathrm{L}$ dNTPs and 1.5 units Taq DNA Polymerase and $5 \mu \mathrm{L}$ of extracted DNA as template. Thermal cycling parameters were $94^{\circ} \mathrm{C}$ for 5 minutes and 35 cycles of each 1 minute at $94^{\circ} \mathrm{C}, 1$ minute at $55^{\circ} \mathrm{C}$ and 1 minute at $72^{\circ} \mathrm{C}$ followed by final extension at $72^{\circ} \mathrm{C}$ for 10 minutes. Amplified product obtained in PCR assay was of $400 \mathrm{bp}$.

\subsection{Detection of PCR Amplified Products}

For gel based PCR detection amplicons were detected by standard ethidium bromide staining and UV illumination of $2 \%$ agarose gels. 


\subsection{Sensitivity of Assay}

Limit of sensitivity of PCR assays was determined by serial dilutions of the extracted DNA. Dilutions were made in nuclease free water up to $100^{-6}$. Each tube was vigorously mixed, vortexed and spinned after each dilution. PCR was run for each dilution from $100^{-1}$ to $100^{-6}$ (Figure 1). Replicates were run on PCRs for each of the dilutions (Figure 2). Further eight replicates were run on the last dilution where amplification resulted in clearly visible band on ethidium bromide staining and UV illumination, after electrophoresis in $2 \%$ agarose gel.

\section{RESULT}

The positive sample of Pup No. 18 CPV DNA was properly amplified by the PCR protocol followed. We added $5 \mu \mathrm{L}$ of template/25 $\mu \mathrm{L}$ reaction. Since DNA concentration as reported by spectrophotometric analysis was 8.3 $\mathrm{ng} / \mu \mathrm{L}$ therefore DNA concentration in $5 \mu \mathrm{L}$ template was $(5 \times 8.3) 41.50 \mathrm{ng}$.

The PCR was capable of detecting up to $100^{-4}$ dilution of CPV DNA therefore the detection limit was calculated to be $41.50 / 100,000,000$ i.e. $0.000000415 \mathrm{ng} \cdot 5 \mu \mathrm{L}=0.002 \mathrm{pg}$.

\section{DISCUSSION}

PCR is primer directed enzymatic amplification of specific target DNA sequences. It has become an important part of modern diagnostic methods and for basic research. When used with proper caution and appropriate controls, PCR can provide invaluable help in rapid identification of specific pathogens which are difficult to grow. PCR has been applied for detection of several viruses. Currently, the standard method for diagnosing the presence of viral pathogens in clinical samples relies on culture and other techniques which are time consuming and cumbersome. However, active research is under way using new molecular methods to curtail detection time and increase assay sensitivity. PCR has emerged as the molecular method of choice in achieving these objectives. A PCR-based method cannot be given diagnostic status, until it includes methods to determine minimum detection limit, positive control, negative control and a reagent control (blank). The minimum detection limit and thereby the diagnostic sensitivity of a PCR assay, particularly on sub clinical samples with low target pathogens, depends on an effective sample treatment procedure. Thus by estimating minimum detection limit of a diagnostic PCR one can diagnose a disease condition where infection is in subclinical phase and sample volume is less. In this study we standardized a PCR using reported primers to detect CPV infection. PCR showed good concordance with virus isolation "gold standard" for diagnostic virology, demonstrates specificity and sensitivity of this method. In addition PCR is more eco-

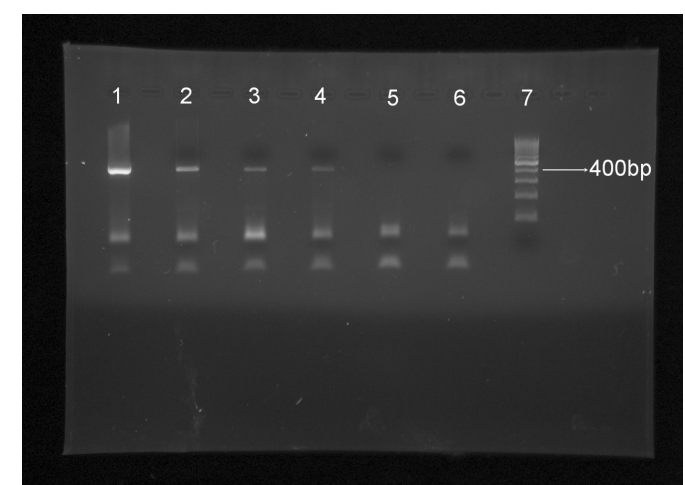

Figure 1. Agarose gel electrophoresis with dilutions PCR products, Lane $1-100^{-1}$, Lane $2-100^{-2}$, Lane $3-100^{-3}$, Lane $4-100^{-4}$, Lane $5-100^{-5}$, Lane $6-100^{-6}$, Lane $7-$ 100 bp marker.

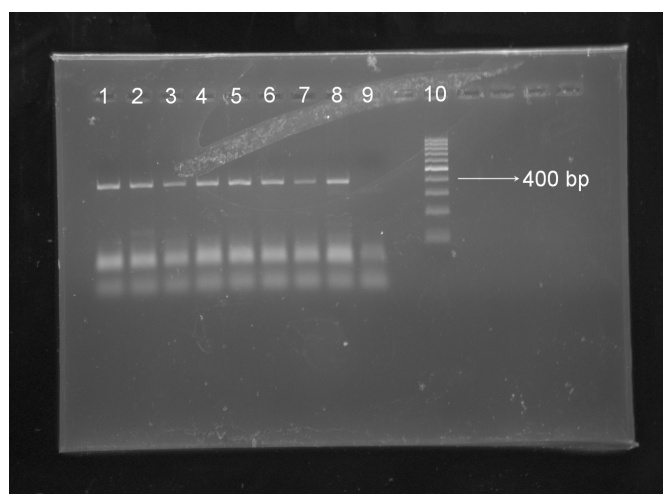

Figure 2. Agarose gel electrophoresis of PCR products of replicates of dilution of $100^{-4}$ of sample DNA, Lane 1 - 8 $-100^{-4}$ dilution of sample DNA, Lane 8-100 bp marker, Lane 9-negative control, Lane 10—100 bp marker.

nomical than virus isolation because it requires neither cell culture facilities nor highly trained specialists.

We got DNA concentration in sample DNA quantified from AIIMS by spectrophotometric analysis. We made dilutions of concentration of the DNA and used these dilutions as template for PCR to calculate the minimum detection limit for the PCR. We calculated the minimum amount of DNA detected by PCR to be $0.002 \mathrm{pg}$ which is very less compared to other methods. When replicates of the minimum detected dilution were run PCR was able to detect the DNA every time demonstrating, specificity, sensitivity and reproducibility of this method. PCR therefore is found to be of immense applicability in diagnosing presence of virus in apparently healthy animals in latent stage or in very early stages, long before symptoms of disease become visible, thus help in controlling infection and formulating policies on prevention and control of disease at a very early stage at right time.

\section{ACKNOWLEDGMENTS}

Authors are grateful to Directorate General Remount Veterinary Ser- 
vices for providing facilities for conduct of this work and to Dr. H. K. Prasad, Professor of Department of Biotechnology AIIMS, for assistance provided.

\section{REFERENCES}

[1] Sagazio, P., Tempesta, M., Buonavoglia, D., Cirone, F. and Bounavoglia, C. (1998) Antigenic characterization of canine parvovirus strains isolated in Italy. Journal of Virological Methods, 73, 197-200.

doi:10.1016/S0166-0934(98)00055-X
[2] Ramadass, P. and Khader, T.G.A. (1982) Diagnosis of canine parvovirus infection by agar gel precipitation test and fluorescent antibody techniques. Cherion, 11, 323-328.

[3] Kumar and Dharmadheeran (2008) Detection of CPV from fecal samples by PCR. Journal of Remount and Veterinary Corps, 47, 197-201.

[4] Narayanan, S., Amit, K., Chug, P.K., et al. (2001) Strain characterization of Indian isolates of Canine Parvo Virus by PCR RFLP. Journal of Remount and Veterinary Corps, 40, 67-74. 